\title{
Comparative Analysis of DC to AC Conversion Cells for Application in PV-linked
}

\section{Grid-connected Modular Multi-level Cascaded Converters}

\author{
Zahra Malekjamshidi, Mohammad Jafari* \\ School of Electrical and Data Engineering, University of Technology Sydney, NSW, 2007, Australia \\ *mohammad.jafari@uts.edu.au
}

\begin{abstract}
This paper provides a detailed analysis of a dc to ac conversion unit as a building block of a modular multilevel converter for grid integration of photovoltaic (PV) systems. Each conversion unit contains a PV-linked multi-active-bridge (MAB) dc-dc converter followed by a grid-connected single-phase cascaded inverter. Using MAB topology can reduce the size and cost of the entire system as more conversion cells are connected to the same transformer. To integrate the PV outputs and maintain the maximum power point tracking (MPPT), different conversion cell topologies are feasible for the MAB converter. This paper provides a comparison between the feasible topologies of the conversion cells in terms of the conversion efficiency, reliability, power transfer ability, cost, size, control complexity and generated ripple. The steady-state operation and the control technique of the selected topology are presented in detail. Some control techniques are introduced to improve the system's efficiency and MPPT performance of the conversion cell. A prototype of the conversion cell is developed to validate the proposed topology and the control techniques.
\end{abstract}

\section{Introduction}

Nowadays there is an increasing interest in the photovoltaic (PV) renewable energy systems due to the continuous improvement in their performance and reduction of the installation cost [1]. To integrate the low-voltage (LV) PV systems into the medium-voltage (MV) distribution networks, modular multi-level converters (MMCs) have been the most promising topology [2], [3]. They have presented many advantages such as utilizing low rating switching components for high voltage applications, reliability and redundancy due to the modular structure, galvanic isolation and compact size [4]. Other advantages are lower generated harmonics and electromagnetic interference and high compatibility with the smart-grid control techniques [4], [5]. The structure of the MMCs contains several dc-ac converter units connected in series to form each phase of the three-phase system. Each converter unit contains a dc-dc converter to boost the voltage of the PV panels and maintain the maximum power point tracking (MPPT) followed by a cascaded grid-connected single-phase inverter [5]. Dual active bridge (DAB) topology has been widely used at the dc-dc conversion stage due to the simple structure and control, soft-switching capability and high efficiency [4], [6]. It has been used as a building block in the dc-dc conversion stage of the modular smart transformers [7]. The DAB converter topology was introduced in [8] and it includes two full-bridge dc-ac conversion cells linked to a high-frequency transformer. The topology can be further extended to the multi-active bridge (MAB) converter by connecting more active bridges to a multi-winding transformer (MWT) [9]. The resultant topology leads to a reduced number of conversion cells and transformers which reduces the system size and cost of the system, while still preserves the same advantages [10]. The multi-winding transformer (MWT) operates as a common magnetic bus to integrate the energies in the form of magnetic flux [11]-[13]. The power flow in the MWT is controlled by a phase shift control technique [9]-[13]. The most common MAB converter topologies are triple-active bridge (TAB) [12], and quadrupleactive bridge (QAB) [13]. However, increasing the number of bridges and transformer windings to more than four leads to the complexity in the structure and design of MWT [14], [15]. Application of MAB converter with different configurations in the modular smart transformers and the resulting advantages are studied in [10] and only the full-bridge topology is considered as dc-ac conversion cell in the proposed systems. However, some other dc-ac conversion cells that are feasible for MAB converter application are suggested in [16]. The most common topologies employed for this application are full-bridge (FB) [17], half-bridge (HB) [18], current-fed half-bridge (CFHB) [19] and current-fed fullbridge (CFFB) [20]. A CFHB conversion cell is proposed in [21] for high power PV-linked converters to reduce the size and cost of the system. However, start-up circuits are required to control the converter at the starting time as the duty cycle in this topology can never be less than $50 \%$ [4]. A topology of PV-linked MMC based on the DAB converter is proposed in [20]. However, the topology can be further simplified by combining the $\mathrm{DAB}$ converters into the $\mathrm{MAB}$ configuration as suggested in this paper.

To select a proper topology of conversion cell, the characteristics of the cell such as reliability, efficiency, cost and size play an important role due to the modular structure of the converter. Furthermore, some other factors such as generated current ripple and MPPT capability are of important factors in the case of the PV-linked converter. Due to the intermittent nature of irradiation level and temperature, the maximum power extracted from a PV port is variable and depends on climatological conditions [22]. Therefore, the conversion cell should be able to maintain the maximum power point tracking (MPPT) of the PV panel [23]. On the other hand, the PV output voltage level is low and needs to be boosted before applying to the inverter stage. The selected topology also should generate minimum current ripple on the PV output as high current ripple deteriorates the MPPT performance and the PV panel efficiency [24],[25]. The boost dc-dc converters have been conventionally used to step up the PV output voltage and realize the MPPT [26], [27]. However, a dc-ac converter is still required to link the PV output to the MWT. 


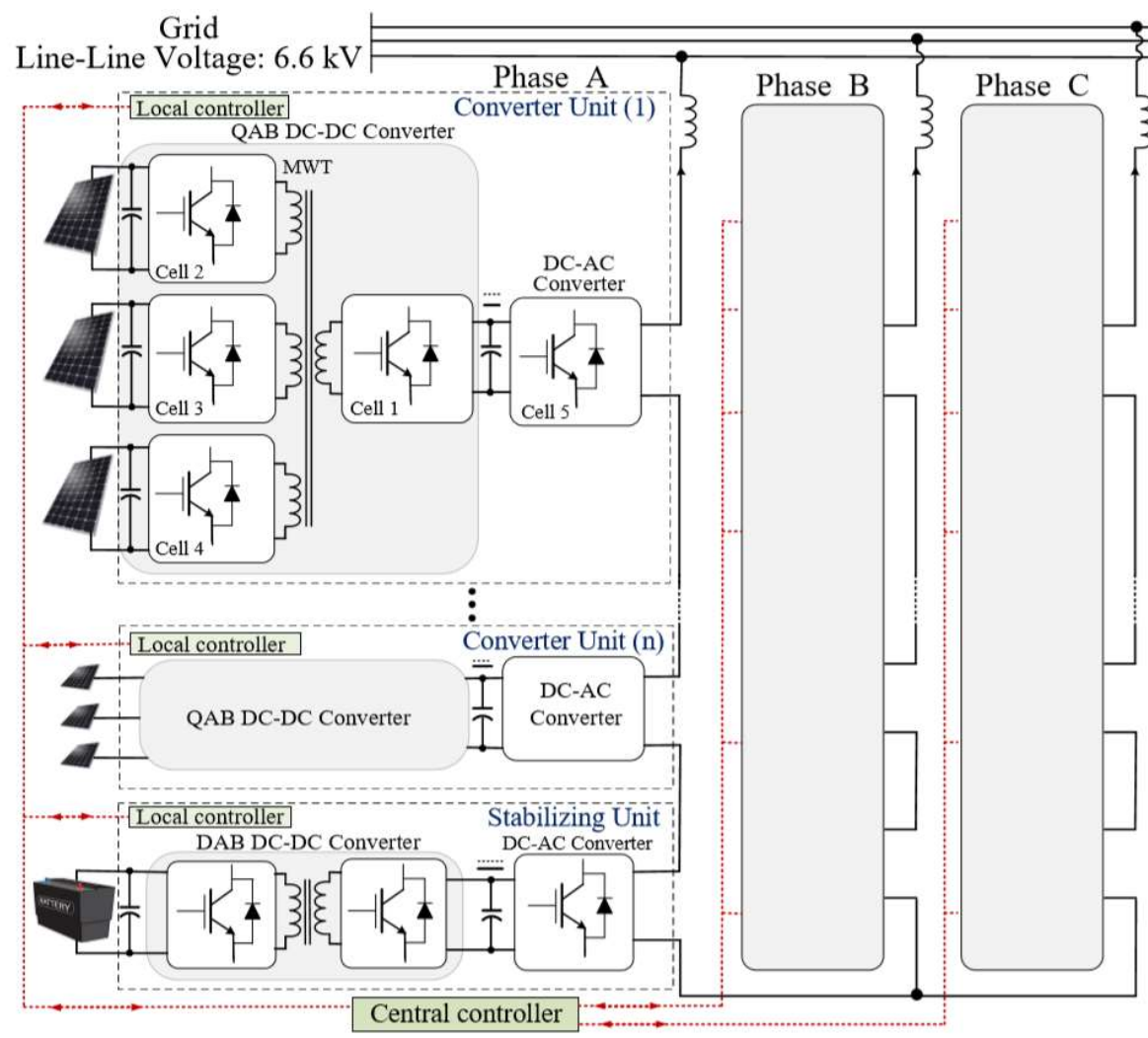

(a)
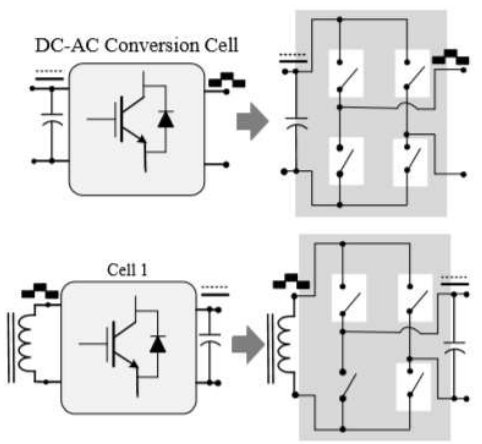

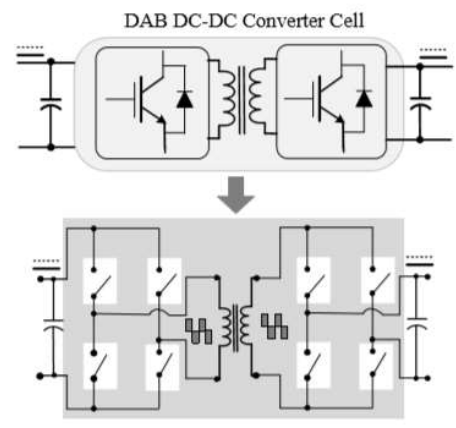

(b)

Fig.1. (a) Structure of the proposed modular multi-level converter and (b) detailed schematic of each conversion cell

In this paper, a topology of a PV-linked grid-connected MMC is proposed as presented in Fig.1. As can be seen, each phase of the converter includes a series connection of multiple converter units and each unit includes a MAB dc-dc converter (either TAB or QAB topology) followed by a cascaded singlephase inverter. The DC-DC or DC-AC conversion cells are mainly full-bridge topologies as presented in more detail in the fig.1.(b). However, in the case of PV-linked DC-AC conversion cells (cell 1,2 and 3) there are several feasible topologies including FB, HB, CFHB and CFFB. Therefore, a comparative analysis is performed to select a proper topology of the dc-ac conversion cell for the MAB converter from these topologies. The main features of the topologies in terms of efficiency, power transfer range, switching loss, size, cost, reliability and generated current ripple are compared. The selected converter unit then is studied in more detail for steady-state operation and control technique. Several control techniques are used to improve the performance of the converter unit. A synchronized voltage balance (SVB) technique is used to reduce the root-mean-square (RMS) and the peak value of currents in the windings of the transformer and switching devices and improve the converter efficiency. A resonant-proportional-integral (PIR) compensator is used in the control system to reduce the low-frequency ripple propagated from inverter output on the PV bus and improve the MPPT performance.

The presented comparison in this paper takes more parameters into account in contrast to the previously published papers. Furthermore, the results can be used for other applications such as modular smart transformers, multi-level converters, and multi-active bridge converters.
The rest of the paper is organized as follows. The comparative analysis of the feasible topologies and selection of appropriate conversion cell is presented in section 2. The steady-state operation and control technique of the selected topology are studied in section 3 and 4 , respectively. The experimental test results are presented in section 5 . Conclusions are derived in section 6.

\section{Selection of DC to AC Conversion Cell}

The topology of the proposed grid-connected PV-linked converter is presented in Fig.1. As can be seen, the system includes three-phase wye-connected $\mathrm{dc}$ to ac PV-linked conversion legs. Each leg (as presented for phase A) contains $n$ cascaded converter units to transfer the energy generated by the PV panels to the utility grid. Each individual unit includes a PV-linked MAB dc-dc converter followed by a cascaded single phase inverter. A stabilizing unit provides a bidirectional power flow by linking a battery to each phase through a DAB dc-dc converter followed by a bidirectional inverter. The proposed unit is used to balance the phase voltage in transients and compensate for the solar shading effects. The DAB converter topology is well-stablished and studied in the literature [28]. It includes two half bridge dc-ac converters interlinked by a high-frequency transformer and the bidirectional power flow control can be achieved easily by a phase shift control technique. The power flows from the battery to the inverter and output line when there is not enough $\mathrm{PV}$ generation. In the case that the PV generation is more than required power, it is absorbed by the battery by reversing the power flow direction and operation of the inverter as rectifier. The battery in this research is selected a lead-acid battery that 
is selected due to the characteristics, cost and availability.

The MAB converter includes multiple dc-ac conversion cells (presented as Cell 1 to 4) which can be in the form of FB, $\mathrm{HB}, \mathrm{CFFB}$ or CFHB topologies. The performance of the conversion cell is important in the quality of the entire system due to the modular structure. A comparative study is presented in this section to select the proper conversion cell for the MAB converter. From an analytical point of view, any $n$-port MAB converter can be decomposed into $n(n-1) / 2 \mathrm{DAB}$ converter [10]. Therefore, the DAB converter is used as a base topology to simulate and compare the characteristics and performance of the conversion cells. The simulation circuit is presented in Fig.2. The left-hand side cell can be selected as one of the FB, $\mathrm{HB}, \mathrm{CFHB}$ or CFFB topologies as presented in Fig.3. The simulation results are used to evaluate and compare the performance of the topologies. The compared features include the power transfer range, efficiency, switching loss and generated current ripple. The circuit parameters are selected as: $V_{l}=V_{2}=100 \mathrm{~V}, P_{12}=70 \mathrm{~W}, N_{l}=N_{2}=10, L_{l}=L_{2}^{\prime}=0.01 \mu \mathrm{H}$, $L_{m}=50 \mathrm{mH}, r_{L 1}=r_{L 2}=0.01 \Omega$, and $R_{m}=50 \Omega$ and realcharacteristic switches are considered. Other effective factors such as estimated cost and size of the topologies, reliability, and the control complexity also have been considered. Following sections provide more detail on each of the compared parameters.

\subsection{Cost of the Topologies}

The cost of the conversion cells can effectively determine the total cost of the converter due to the modular structure. To estimate the cost of the topologies, the number of the main components such as switching device, diode, capacitor, inductor and transformer and their average price in the market for each range of power has been taken into account. The total cost of the topologies is roughly calculated for a nominal power ranges from $1 \mathrm{~kW}$ to $5 \mathrm{~kW}$ as presented in Fig.4 (a). It can be seen that the total cost for the CFFB topology is the highest and the FB topology is the lowest for all ranges of the rated power. Therefore, the normalized cost factors for FB, HB, CFHB and CFFB topologies can be estimated as 1, 0.86, 0.72 and 0.61 respectively where the higher value of the cost factor is given to the lowest cost.

\subsection{Power Transfer Efficiency}

This factor is defined as the ratio of the power transferred from source $V_{1}$ to $V_{2},\left(P_{12}\right)$ to the input power $\left(P_{1}\right)$ for phase shift angle ranges between 0 to $\pi / 2$. As illustrated in Fig.4 (b), at the lower phase shift angles, the power transfer efficiency decreases in all types of topologies as transferred power is comparable to the switching and conduction losses. The HB, $\mathrm{FB}$, and $\mathrm{CFHB}$ topologies presented higher efficiency compared to that of CFFB, especially for lower phase shift angles.

\subsection{Single Switch Power Loss Ratio}

The switching loss is another indicator to study the performance of the topologies and is defined as the ratio of loss in a single switch to the input power maintaining the same load conditions for all topologies. As illustrated in Fig.5 (a), the switching loss of HB and CFHB are slightly higher than that of CFFB and FB. However, the ratio of loss to input power increases in all topologies at lower phase shift angles (Less than $\pi / 12)$.

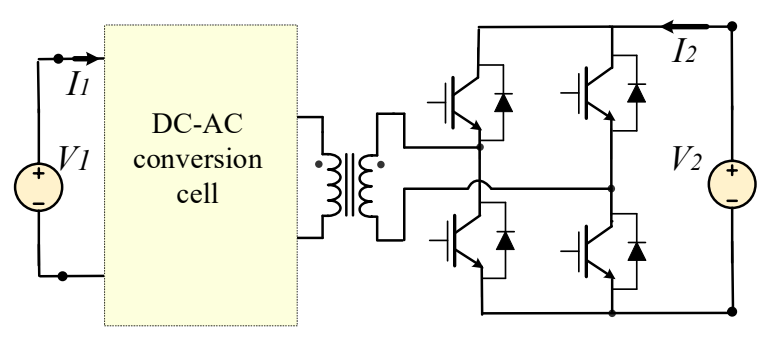

Fig.2. Simulation circuit of DAB converter using PSIM
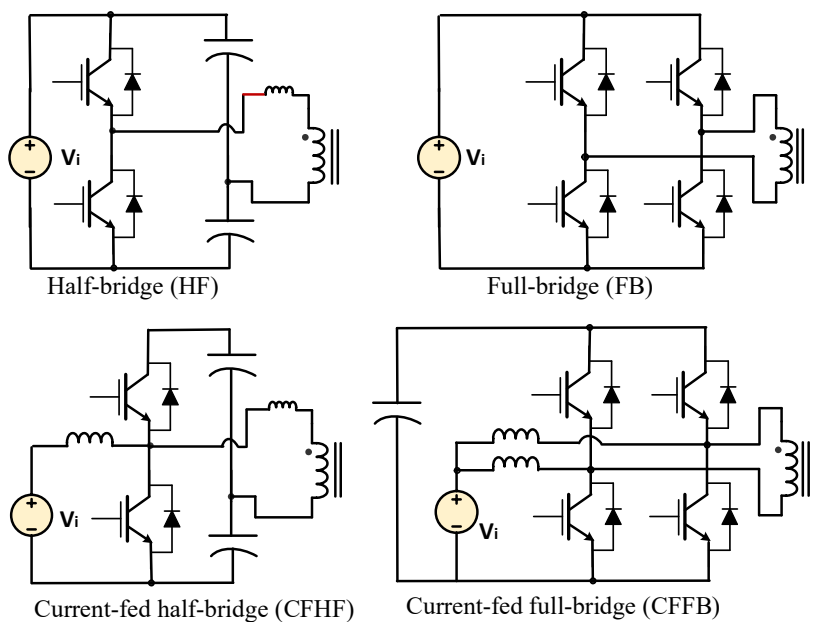

Fig.3. The simulated dc-ac converter cells

\subsection{Generated Current Ripple}

The percentage of the generated ripple in the current received from the input voltage source is an important factor due to the effect on the PV operation and MPPT performance. The ripple factor at different phase shift angles is determined for the topologies from

$$
R(\text { ripple }) \%=100 \cdot \sqrt{\left(\frac{I_{r m s}}{I_{a v}}\right)^{2}-1}
$$

where $I_{r m s}$ is the root-mean-square (RMS) and $I_{\text {avg }}$ the average current received from the PV output. The ripple factor is determined without using a low-pass filter to indicate the nature of the topologies. As presented in Fig.5 (b), the current ripple increased for all topologies for small phase shift angles (Less than $\pi / 12$ ). However, CFFB presented the lowest, and $\mathrm{FB}$ and HB topologies presented the highest ripple for higher phase shift angles.

\subsection{Power Transfer Range}

The power transfer range is defined as the amount of power transferred from port one to port two $\left(P_{12}\right)$ based on the phase shift angle assuming same input power for all topologies. The transferred power for all topologies is normalized to the CFFB topology as the highest value for easier comparison as illustrated in Fig.6 (a).

\subsection{Size of the Topologies}

The occupied size of the topologies is an important factor, particularly in modular systems. In this paper, the size of the topologies are estimated by integrating the average size of the main components of each topology from 
Table 1 Failure rate and life time for the main components

\begin{tabular}{l|ccc}
\hline \multicolumn{1}{c|}{ Component } & IGBT & Capacitor & Inductor \\
\hline $\begin{array}{l}\text { Failure Rate } \\
\text { (/1000000 hours) }\end{array}$ & 0.241 & 1.071 & 0.012 \\
Life time (hour) & 458,000 & 125,000 & $2,153,000$ \\
\hline
\end{tabular}

Table 2 Comparison of reliability factor for four topologies

\begin{tabular}{c|cccc}
\hline $\begin{array}{c}\text { Topology } \\
\text { Parameter }\end{array}$ & FB & HB & CFHB & CFFB \\
\hline MTBF & $1,037,344$ & 381,097 & 379,362 & 648,200 \\
$\begin{array}{c}\text { Life time } \\
\text { (hrs) }\end{array}$ & 458,000 & 125,000 & 125,000 & 260,000 \\
$\begin{array}{c}\text { Reliability } \\
\text { Factor }\end{array}$ & 1.00 & 0.74 & 0.62 & 0.84 \\
\hline
\end{tabular}

Table 3 Complexity factors of the topologies

\begin{tabular}{l|cccc}
\hline $\begin{array}{l}\text { Topology } \\
\text { Complexity element }\end{array}$ & FB & HB & $\begin{array}{c}\text { CF } \\
\text { HB }\end{array}$ & $\begin{array}{c}\text { CF } \\
\text { FB }\end{array}$ \\
\hline $\begin{array}{l}\text { Number of switching } \\
\text { devices }\end{array}$ & 4 & 2 & 2 & 4 \\
$\begin{array}{l}\text { Number of controllable } \\
\text { parameters }\end{array}$ & 1 & 2 & 3 & 2 \\
$\begin{array}{l}\text { Number of driving signals } \\
\text { Number of voltage balance } \\
\text { circuits }\end{array}$ & 2 & 2 & 2 & 2 \\
Complexity factor & 1 & 2 & 2 & 1 \\
\hline
\end{tabular}

$$
K_{V}=1.2\left(\sum_{i=1}^{N_{k}} A_{i}\right) h_{\max }
$$

where $A_{i}$ is the seated area of $i$-th component on the printed circuit board (PCB) and $h_{\max }$ the height of the highest component. A $20 \%$ additional area is considered as spare area between the components. Fig.6 (b), shows the estimated size of each topology for different ranges of rated power. As can be seen, the estimated size of the FB topology is less than others because it contains no capacitor and inductor.

\subsection{Reliability Assessment}

The reliability of the topologies is an important factor in the safety and reliability of the entire MMC system due to the modular structure [29], [30]. The reliability assessment of the converters is mainly based on the reliability of their components using either 'parts count' or 'life test' techniques [31]. Reliability is defined as the probability that a system can perform a required function under given conditions for a given time interval and is determined from [31]

$$
R(t)=\exp \left[-\int_{0}^{t} \lambda(x) d x\right]
$$

where $\lambda$ is the failure rate of the system and is defined as the number of failures during a specific test time [30]. In the case of a conversion cell, the failure rate of the cell is determined by the failure rate of its components assuming that a failure in any component results in a system failure [31]. Therefore, the failure rate of each conversion cell $\left(\lambda_{s}\right)$ is the sum of failure rates of all included components (according to probability theory) and is defined from

$$
\lambda_{s}=\sum_{j=1}^{m} \lambda_{j}
$$

where $\lambda_{j}$ is the component failure rate per million hours [31] Normally, it is assumed that the component failure rate is constant for the time period considered which seems to be realistic for most of electronic components. The failure rate of the components can be defined for a period of one million hours according to the military handbook of MIL-HDBK$217 \mathrm{~F}[32]$ and is calculated by

$$
\lambda_{j}=\lambda_{b} \prod_{k=1}^{n} \pi_{i}
$$

where $\lambda_{b}$ is the base failure rate of the component and $\pi_{i}$ the $i$ th modification factor which modifies the base failure rate according to the environmental and operational conditions [30], [33]. The main factors that need to be considered are operating temperature, Electrical stress (voltage and current), mechanical stress and operation mode (continuous, periodic or intermittent). However, in this paper, almost the same operation temperature and mechanical stress are considered for all topologies and the results of numerical simulation are used for electrical stress and operation mode.

To determine the failure rate of each topology, the failure rate and the lifetime of the main components of the topologies in operating temperature $\left(\mathrm{T}=70{ }^{\circ} \mathrm{C}\right)$ are evaluated as presented in Table 1. Fig.7 illustrates the main stages of reliability assessment in brief. The resultant values of reliability for all topologies are normalized to represent the reliability factors as presented in Table 2. The FB topology presented the best reliability as it does not have any installed capacitors as the less reliable components.

\subsection{Complexity Assessment}

To compare the complexity of the topologies, some indicators such as the number of switching devices, driving signals, required voltage balance circuits and the parameters that need to be controlled (voltage or current) have been taken into account. The reason that the number of the switching device is considered as a complexity indicator is that each switching device needs a gate drive circuit which increases the complexity of the conversion cell. The complexity factors of the topologies are presented in Table 3 and the topology with less complexity obtained a higher grade.

To do the overall assessment, the above mentioned evaluated factors are normalized considering maximum and minimum values for all the topologies by

$$
X_{i}(\text { norm })=\frac{X-X_{\min }}{X_{\max }-X_{\min }} \quad, 0 \leq X_{i}(\text { norm }) \leq 1
$$

where $X_{i}$ (norm), $X_{\max }, X_{\min }$, and $X$ are the normalized, maximum, minimum and actual value of the parameter, respectively. The normalized values for each topology then are added together by applying appropriate weighting factors. The weighting factor $\left(\delta_{i}\right)$ for each parameter represents the importance of the parameter in the final assessment considering the design objectives and operation conditions. In this paper the weighting factors are selected according to the PV-linked conversion cell requirements and current ripple, reliability, efficiency and power transfer range received the maximum importance. The summation of all weighting factors should be equal to one. The normalized evaluation factors of the topologies and the selected weighting factors are illustrated in Tables 4 and 5. To find the best topologies 

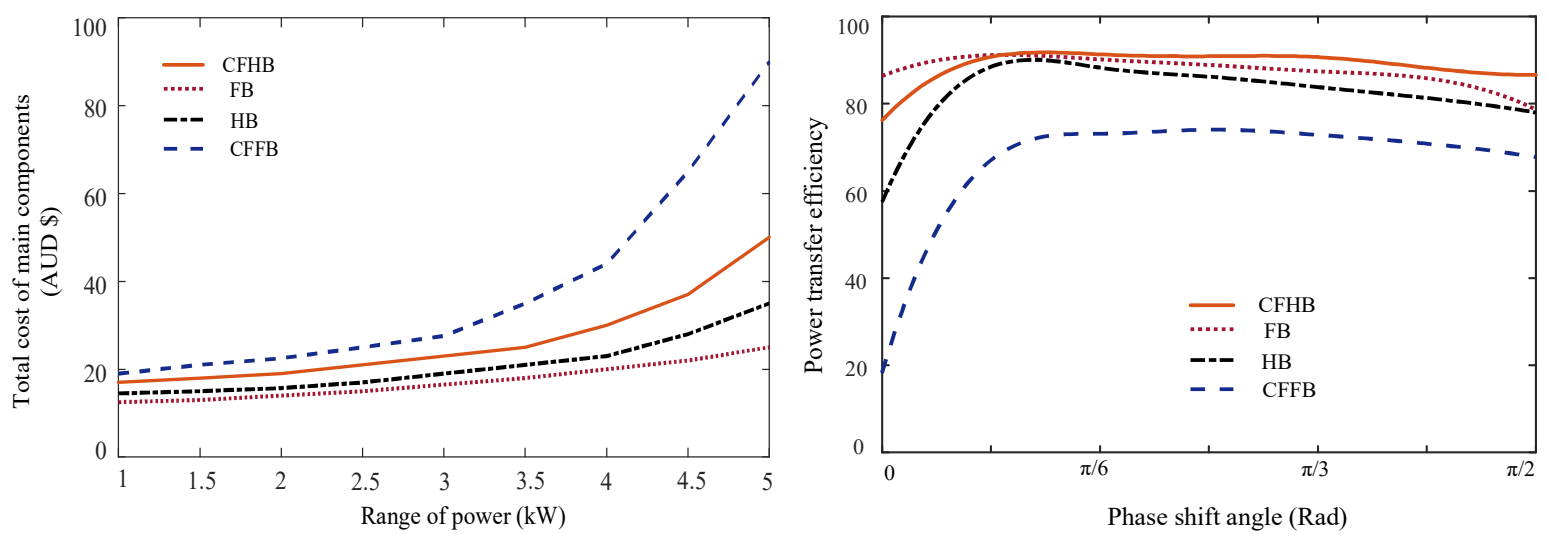

Fig.4. (a) total cost of topologies versus range of power and, (b) power transfer efficiency of topologies versus phase shift angle
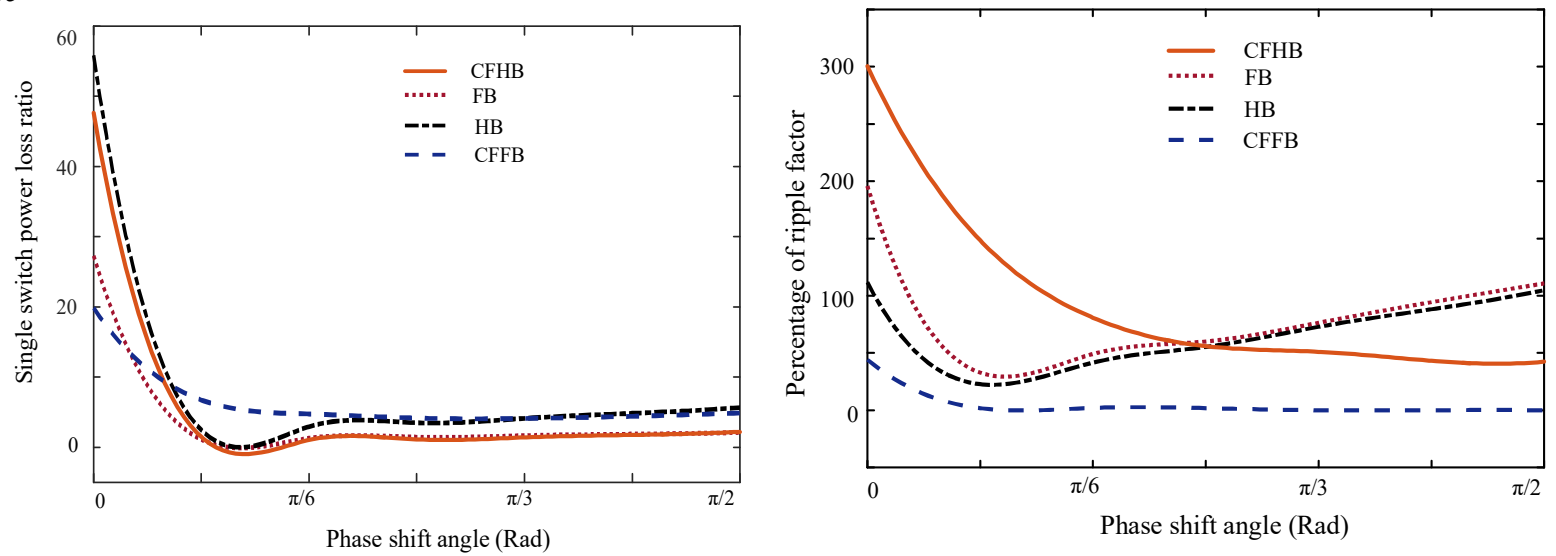

Fig.5. (a) single switch power loss of the topologies and, (b) percentage of ripple factor versus phase shift angle
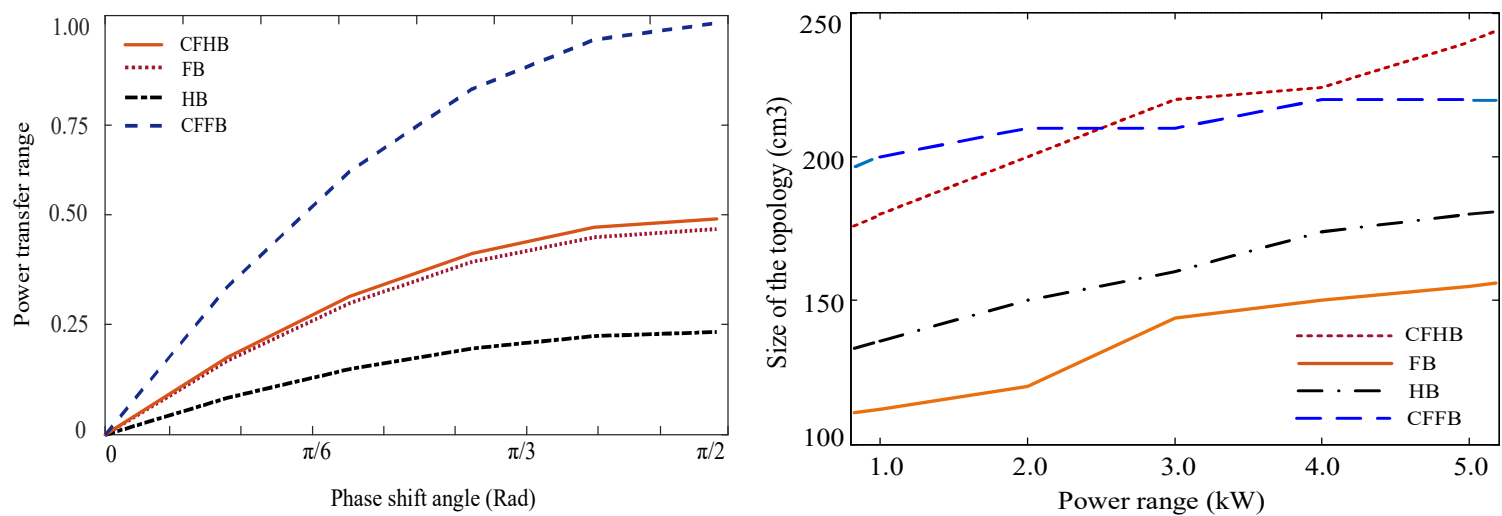

Fig.6 (a) power transfer range of the topologies versus phase shift angle and, (b) size of the topologies based on the power range.

according to the design objectives, the normalized weighted parameters can be presented in the form of evaluation charts for all topologies as presented in Fig.8. The proper topology then can be selected based on the covered area in the evaluation chart. Alternatively, the overall evaluation factor, $\left(K^{*}\right)$ for each of the topologies can be calculated by summing up all effective factors multiplied by their weighting factor from

$$
K^{*}=\sum_{i=1}^{n}\left[\delta_{i} \cdot X_{i}(\text { norm })\right]
$$

Finally, the evaluation factor of the FB, HB, CFHB and CFFB topologies is determined as $0.831,0.716,0.781$, and 0.875 , respectively. performance and is selected as the appropriate conversion cell topology for the proposed PV-linked converter. This also can be found from the presented evaluation charts. Furthermore, it provides more flexibility for simultaneous power flow and the MPPT control as will be discussed in the next section.

\section{Steady State Operation of the Converter Unit}

This section provides a detailed analysis of the converter unit including a PV-linked QAB dc-dc converter and a gridconnected single-phase inverter as a building block of the PVlinked MMC (referring to Fig.1). Three CFFB conversion cells presented as cell 2, 3 and 4, are used to boost the PV outputs to the HVDC bus and the inverter. As discussed in section 2, the CFFB topology presented the minimum ripple 


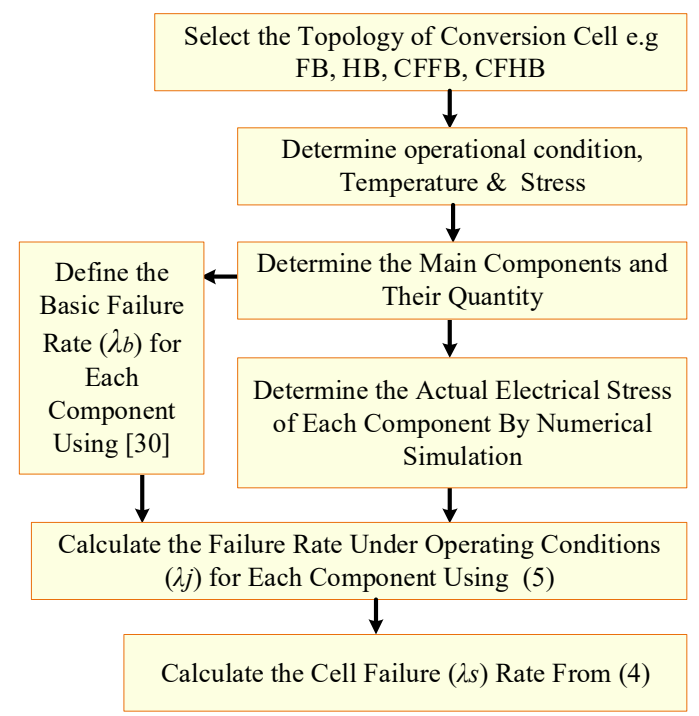

Fig. 7. Reliability assessment diagram for the conversion cells

Table 4 Normalized parameters of three topologies

\begin{tabular}{l|cccc}
\hline $\begin{array}{c}\text { Topologies } \\
\text { Evaluation parameters }\end{array}$ & FB & HB & CFHB & CFFB \\
\hline Cost & 1.00 & 0.86 & 0.72 & 0.61 \\
Size & 1.00 & 0.80 & 0.70 & 0.60 \\
Reliability & 1.00 & 0.74 & 0.62 & 0.84 \\
Control complexity & 1.00 & 0.80 & 0.70 & 0.90 \\
Current ripple & 0.50 & 0.50 & 0.80 & 1.00 \\
Switching loss & 0.80 & 1.00 & 0.80 & 1.00 \\
Efficiency & 0.95 & 0.90 & 1.00 & 0.80 \\
Power transfer range & 0.80 & 0.60 & 0.80 & 1.00 \\
\hline
\end{tabular}

Table 5 Weighting factors for evaluation

\begin{tabular}{lclc}
\hline $\begin{array}{l}\text { Evaluation } \\
\text { parameter }\end{array}$ & $\begin{array}{c}\text { Weighting } \\
\text { factor }\end{array}$ & $\begin{array}{l}\text { Evaluation } \\
\text { parameter }\end{array}$ & $\begin{array}{c}\text { Weighting } \\
\text { factor }\end{array}$ \\
\hline Cost & 0.10 & Current ripple & 0.23 \\
Reliability & 0.18 & Size & 0.05 \\
Efficiency & 0.16 & $\begin{array}{l}\text { Control } \\
\text { complexity }\end{array}$ & 0.05 \\
Switching loss & 0.05 & $\begin{array}{l}\text { Power } \\
\text { transfer range }\end{array}$ & 0.18 \\
\hline
\end{tabular}

on the PV output current which is an important factor for the MPPT performance [4]. It can be modelled as the interleaved boost converters cascaded by a voltage source full bridge dc to ac converter as presented in Fig.9. The full bridge switches $S_{1}, S_{2}, S_{3}$ and $S_{4}$ have been shared in both converters and $C_{2}$ is used as an energy buffer between the two conversion stages. The PV voltage is boosted by the interleaved converters and the extracted PV power is sent to $C_{2}$ and low-voltage dc (LVDC) bus $\left(V_{L V D C}=V_{C 2}\right)$

The conversion cell should be designed to operate in continuous conduction mode (CCM) for the whole operation range. This minimizes the ripples on the current derived from the PV panel due to the interleaving effect. To realize the MPPT, the duty ratio of $S_{3}$ and $S_{4}$ is changed according to the MPPT algorithm to adjust the output voltage from PV $\left(V_{P V}\right)$ on the desired value. The full bridge dc-ac converter then changes $V_{L V D C}$ to a rectangular high-frequency voltage $\left(v_{t}\right)$ linked to the transformer winding.

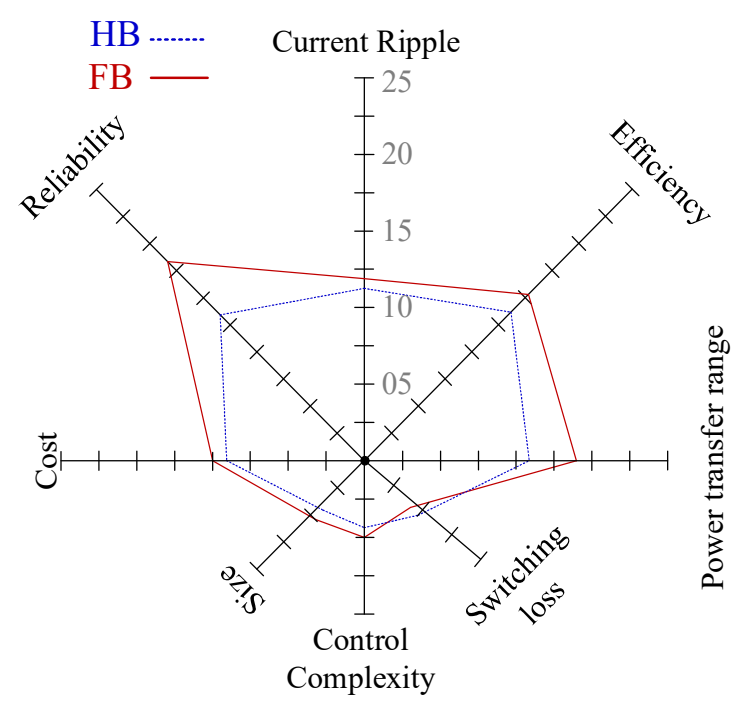

(a)

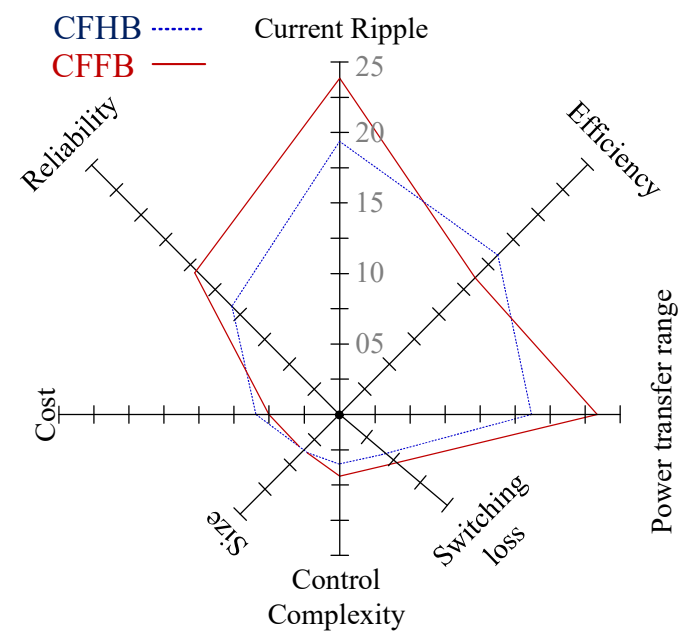

(b)

Fig.8. The characteristics evaluation chart of topologies. (a) $H B$ and $F B$. (b) $C F H B$ and $C F F B$.

The relation between the duty cycle of $S_{3}$ or $S_{4}$ (presented as $D$ ) and duty cycle of $v_{t}$ (presented as $\left.D^{\prime}\right)$ is defined as

$$
D^{\prime}=\left\{\begin{array}{cc}
2 D & D<=0.5 \\
2(1-D) & D>=0.5
\end{array}\right.
$$

On the other hand, a square wave voltage $\left(V_{t 1}\right)$ with the same frequency is generated from the high-voltage dc bus $\left(V_{H V D C}\right)$ by full bridge in cell 1 . Fig. 10 shows the waveforms of the voltage and current in the CFFB conversion cell where $D=0.4$, $D^{\prime}=0.8$, and $\varphi_{21}=\pi / 6$. The waveforms of other conversion cells are similar assuming almost similar irradiation and temperature for all PV panels connected to the same converter unit. The power flow between the PV-linked conversion cell " $\mathrm{X}$ " (where $\mathrm{X}=2,3$ and 4 ) to cell 1 presented as $P_{X I}$ is controlled by a leading phase-sift $\varphi_{X I}$ and can be calculated from [34]

$$
P_{X 1}=\frac{V_{H V D C} V_{L V D C}}{2 \pi^{2} f_{s} n_{X 1}\left(L_{X}+L_{1}^{\prime}\right)}\left[\varphi_{X 1}\left(\pi-\varphi_{X 1}\right)-0.25 \pi^{2}\left(1-D^{\prime}\right)^{2}\right]
$$




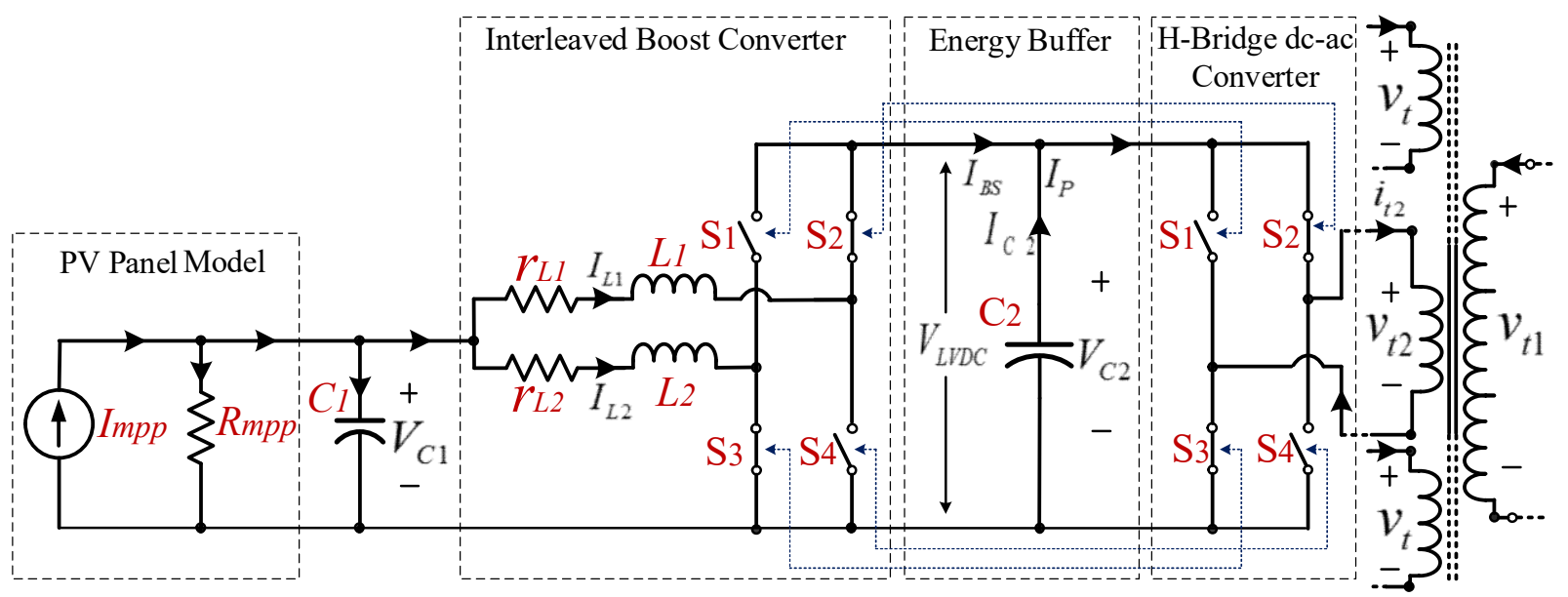

Fig.9. The equivalent circuit of the PV-linked $C F F B$ conversion cell

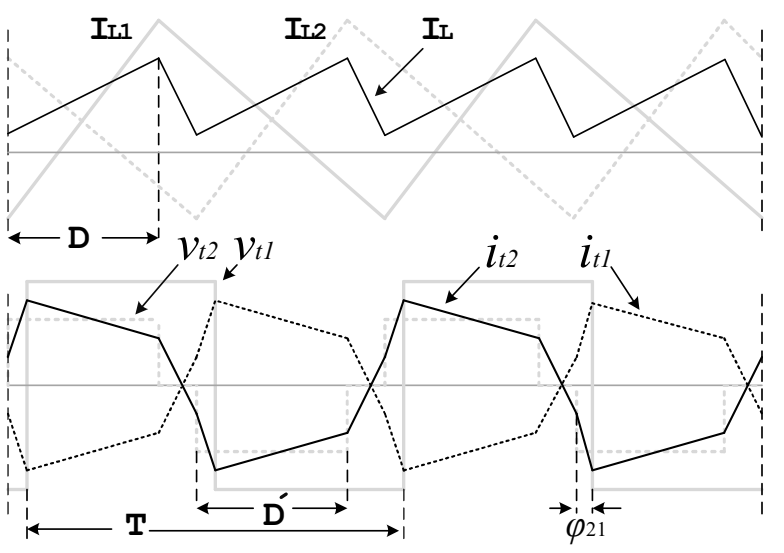

Fig.10. The waveforms of the conversion unit

where $V_{H V D C}, f_{s}, L_{X}$ and $L_{l}^{\prime}$ are respectively the dc voltage of the inverter bus, switching frequency, the leakage inductance of the transformer winding linked to the conversion cell " $X$ " and the referred value of leakage inductance of the winding in cell 1. Furthermore, $n_{X I}=N_{X} / N_{1}$ represents the turns ratio of winding $X$ to one. As $D$ is changed independently according to the MPPT requirement, $D^{\prime}$ is dependent on $D$ and cannot be used to control the power flow. Therefore, the phase shift angle $\left(\varphi_{X I}\right)$ is used as another degree of freedom to regulate $V_{L V D C}$ on the desired value and also control the power flow between the PV-linked cells and cell 1. Fig.11 (a) shows the variation of $V_{\mathrm{C} 2}$ for a wide range of duty cycle and phase shift angle, $\varphi$. However, the variation range of $\mathrm{D}$ and may be limited for some dc bus voltages. Fig.11 (b) shows that the variation range for $V_{b u s}=40 \mathrm{~V}$ is much less than the $V_{b u s}=120$ $\mathrm{V}$. The operation modes of the MAB converter depends on the variation range of duty ratio $D$ (from 0 to 1 ) and phase shift angle $\varphi$ (from 0 to $\pi$ ). In the proposed converter the practical phase shift angle is less than $\pi / 2$, and the duty cycle, $D$, is changed around 0.5 to achieve higher efficiency [4]. The ZVS operation mode of the converter is in a limited range although, in the case of equal volt-second for all windings of the magnetic link, ZVS operation is guaranteed. To minimize the RMS and peak current and consequently the conduction loss in the transformer winding and guarantee a full range of ZVS operation for all conversion cells, the volt-second product on all windings of the MWT should be kept equal [4], [34].

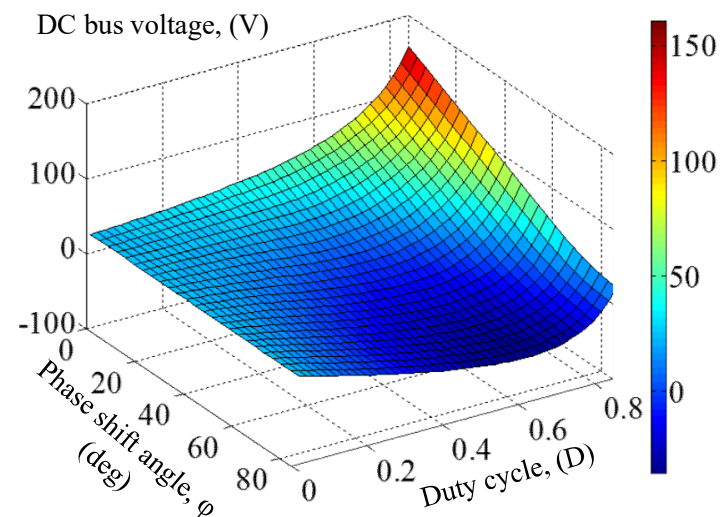

(a)

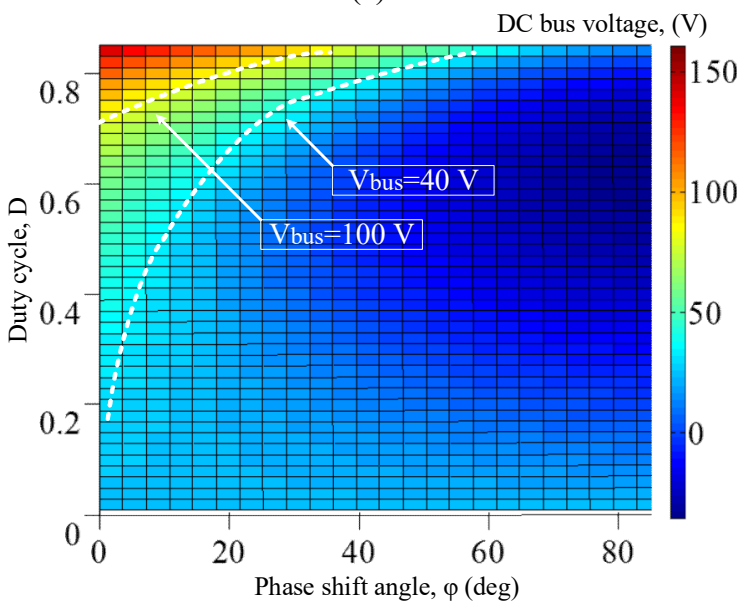

(b)

Fig.11. Variation of $d c$ voltage of the PV port based on the duty cycle and phase shift angle

Therefore, $V_{L V D C}$ is adjusted according to the $V_{\mathrm{HVDC}}$ level at the inverter side. This is known as synchronized voltage balance (SVB) technique. The reference voltage for the LVDC bus in the cell $\mathrm{X}\left(V_{L V D C, X}^{*}\right)$ is defined from

$$
V_{L V D C, X}^{*}=\frac{n_{X 1}}{D} V_{H V D C}
$$

The capacitor $\mathrm{C}_{2}$ is used as an energy storage component and buffer between two conversion stages. However, it needs to be 
selected properly to cancel out the low-frequency $(2 \omega)$ voltage ripples reflected from the inverter output on the HVDC bus and the PV output. A proper design can significantly improve the MPPT performance. The minimum value of required capacitance depending on the voltage ripple $\left(\Delta V_{\text {ripple }}\right)$ and $V_{\text {LVDC }}$ is determined by [4]

$$
C_{1}=\frac{v_{m} i_{m}}{\omega_{g}\left(V_{L V D G \text { max }}-V_{L V D C \text { min }}\right)\left(V_{L V D G \text { max }}-V_{L V D G \text { min }}\right)}=\frac{P_{o}}{\omega_{g} V_{L V D C}\left(\Delta V_{\text {ripple }}\right)}
$$

where $v_{m}$ and $i_{m}$ are the peak value of the inverter output voltage and current, $\omega_{g}$ the grid frequency and $\Delta V_{\text {ripple }}$ the reflected voltage ripple. It should be noted that to maximize the utilization factor of the PV panels; the voltage ripple is recommended to be less than $8.5 \%$ [35].

The output voltage of the PV panels does not change in a wide range due to the irradiation and temperature levels and the main effect is on the output current. Therefore, the maximum power point (MPP) is changing in the PV panel which needs to be tracked accordingly using an appropriate MPPT algorithm. An efficient MPPT method should provide a fast and accurate tracking response with minimum oscillations around the steady-state operating point for a wide range of variations in the solar irradiation and temperature levels. Therefore, a large number of MPPT algorithm can be found in the literature [36]. In this paper, the incremental conductance (INC) method is used due to the accuracy and minimum effects on the PV operating point. To improve the dynamic response of the method a variable step size algorithm is employed [36]. The step size is automatically adjusted according to the distance between the current operation point and maximum power point. The step size increases when the operating point is far from MPP, and it decreases when the operation point is near to the MPP. The steps are applied directly to the duty ratio of the interleaved converter to adjust the output voltage of the PV on the MPP voltage $\left(V_{m p p}\right)$. Each step change in duty ratio is calculated by the voltage and power of the PV port at $k$ and $k$-1 sampling times from

$$
D^{*}(k)=D^{*}(k-1) \pm N(k)\left|\frac{P(k)-P(k-1)}{V(k)-V(k-1)}\right|
$$

where $N(k)$ is the scaling factor that is used to adjust the step size efficiently and $\mathrm{P}(k)=V(k)^{*} I(k)$ the $\mathrm{PV}$ power at the sampling time $k$.

\section{Analysis and Design of the Control System}

The control system of the proposed MMC includes the local controllers of each converter unit and a master controller which communicates to the smart-grid control center. This section provides a review of the analysis and design of the local controller of each converter unit only. Detail of the master controller operation remains for future publication. Each local controller includes an MPPT control system to maximize the PV output powers, a power flow control system which controls the power flow in the $\mathrm{QAB}$ converter, and a direct current control loop for the single-phase inverter as will be discussed in the following section.

\subsection{Design of the PV Output Controller}

As presented in Fig.9, the PV-linked CFFB conversion cell can be decomposed into the interleaved boost converter followed by a voltage source full-bridge dc-ac converter. To adjust the PV operation point on the MPP, the output voltage
$V_{\mathrm{C} 1}$ should be adjusted accurately according to the MPPT algorithm requirements. The design procedure of the interleaved converter is carried out for a single leg due to the similarity of components and operation principles of two boost converters. To design the controller, a small signal model of the conversion cell is required. As presented in Fig.9, the PV panel is modeled with the Thevenin equivalent circuit at the operation point due to the slow dynamic response of the PV [4]. The equivalent resistor $R_{m p p}$ can be calculated from $R_{m p p}=V_{m p p} / I_{m p p}$ where $V_{m p p}$ and $I_{m p p}$ are the PV panel output voltage and output current at the MPP respectively.

To design a more robust controller for adjusting the PV voltage on MPP, a dual loop control system including inner inductor current and outer PV voltage control loops is proposed. To design the controller, the transfer function of the PV output voltage as the control output to the inductor current as the control input is required. The average state equation of the PV voltage based on the inductor current can be written as

$$
C_{1} \frac{d V_{C 1}}{d t}+I_{L}+\frac{V_{C 1}}{R_{m p p}}-I_{m p p}=0
$$

Adding small signal variations to the equation and considering only the ac elements, the equation can be rewritten as

$$
C_{1} \frac{d \hat{v}_{C 1}}{d t}+\hat{i}_{L}+\frac{\hat{v}_{C 1}}{R_{m p p}}=0
$$

The transfer function of the PV voltage to the inductor current then can be determined using the Laplace transform of (14) as

$$
G_{v-P V}=\frac{V_{C 1}(s)}{I_{L}(s)}=\frac{-R_{m p p}}{1+s C_{1} R_{m p p}}
$$

On the other hand, the state space equations for inductor current over a complete switching cycle can be written as

$$
\left\{\begin{array}{cl}
L_{2} \frac{d I_{L}}{d t}=V_{C 1}-I_{L} r_{L} & 0<t<D T \\
L_{2} \frac{d I_{L}}{d t}=V_{C 1}-I_{L} r_{L}-V_{C 2} & D T<t<T
\end{array}\right.
$$

The final equation by averaging (16) over a complete operating cycle is obtained as

$$
L_{2} \frac{d I_{L}}{d t}=V_{C 1}-I_{L} r_{L}-(1-D) V_{C 2}
$$

Adding the small signal variations and taking Laplace transform, results in the following equation for the inductor current.

$$
I_{L}(s)=G_{i-V} V_{C 2}(s)-G_{i-D} D(s)
$$

where $G_{i-V}$ and $G_{i-D}$ are the transfer functions of the LVDC bus voltage $\left(V_{C 2}\right)$ and the duty cycle $(D)$ to the inductor current respectively and are defined from

$$
G_{i-V}=\frac{V_{C 2}(s)}{I_{L}(s)}=\frac{-D}{s L_{2}+r_{L}}, G_{i-D}=\frac{D(s)}{I_{L}(s)}=-\frac{V_{C 2}}{s L_{2}+r_{L}}
$$

Fig.12 shows the designed dual loop control system. The bandwidth of the inner current control loop should be selected much higher than that of the PV voltage control loop. Therefore, a low-bandwidth control loop with more robustness and stability can be used for PV voltage control. The control blocks $H_{1}(s)$ and $H_{2}(s)$ are the transfer functions of low-pass first-order filters that filter out the high-frequency components of the PV voltage and inductor current respectively and are defined as 


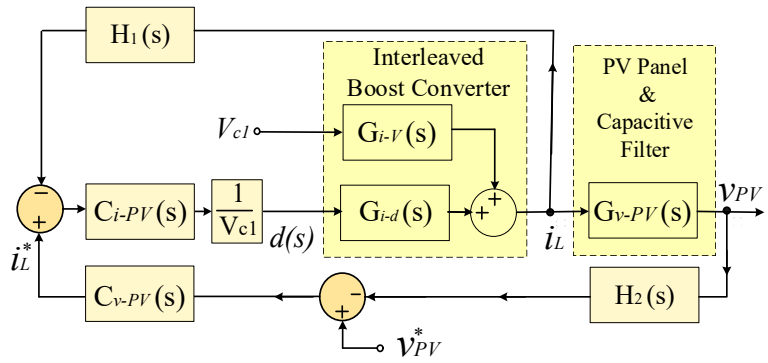

Fig.12. Block diagram of the PV voltage control system

$$
H_{1}(s)=\frac{K_{f 1}}{1+\tau_{1} s}, H_{2}(s)=\frac{K_{f 2}}{1+\tau_{2} s}
$$

where $\tau_{1}=0.95 \mathrm{~ms}$ and $\tau_{2}=0.5 \mathrm{~ms}$ are the time constants of the filters. The feedback gains of $K_{f 1}$ and $K_{f 2}$ are selected according to the signal conditioning circuit parameters. The compensator blocks $C_{v-P V}$ and $C_{i-P V}$ are the proportionalintegral (PI) controller transfer functions of the voltage and current control loops respectively and can be presented in the general form as

$$
C(s)=K_{P}+\frac{K_{I}}{s}
$$

where the proportional $\left(K_{P}\right)$ and the integral $\left(K_{I}\right)$ gains are determined based on the required crossover frequency $\left(\omega_{c}\right)$ and the phase margin $\left(\varphi_{m}\right)$ of the voltage and current control loops [37], [38]. Assuming that the PI controller transfer function is given as

$$
\begin{aligned}
& C(j \omega)=K_{P}+\frac{K_{I}}{j \omega}=K_{P}-j \frac{K_{I}}{\omega} \\
& |C(j \omega)| \angle \theta=|C(j \omega)|[(\cos (\theta)+j \sin (\theta)]
\end{aligned}
$$

Then the design problem is to find $K_{P}$ and $K_{I}$ for a chosen crossover frequency $\left(\omega_{c}\right)$ and phase margin $\left(\varphi_{m}\right)$ such that

$$
C\left(j \omega_{c}\right) G\left(j \omega_{c}\right)=1 \angle\left(180+\varphi_{m}\right)
$$

From (23), we can find the following equations

$$
\begin{aligned}
& \left|C\left(j \omega_{c}\right)\right|=\frac{1}{\left|G\left(j \omega_{c}\right)\right|} \\
& \angle C\left(j \omega_{c}\right)=\theta=180+\varphi_{m}-\angle G\left(j \omega_{c}\right)
\end{aligned}
$$

Finally, from (22) and (24) the values of controller coefficient can be determined as

$$
\begin{gathered}
K_{P}=\left|C\left(j \omega_{c}\right)\right| \cos (\theta)=\frac{\cos (\theta)}{\left|G\left(j \omega_{c}\right)\right|} \\
-\frac{K_{I}}{\omega_{c}}=\left|C\left(j \omega_{c}\right)\right| \sin (\theta)=\frac{1}{\left|G\left(j \omega_{c}\right)\right|} \sin (\theta) \Rightarrow K_{I}=\frac{-\omega_{c} \sin (\theta)}{\left|G\left(j \omega_{c}\right)\right|} \\
\theta=180+\varphi_{m}-\angle G\left(j \omega_{c}\right)
\end{gathered}
$$

Table 6 The PV port parameters for small signal analysis

\begin{tabular}{lcllll}
\hline$C_{1}$ & $100 \mu \mathrm{f}$ & $V_{P V}$ & $10-40 \mathrm{~V}$ & $f_{s}$ & $10 \mathrm{kHz}$ \\
$C_{2}$ & $1200 \mu \mathrm{f}$ & $V_{L V D C}$ & $120 \mathrm{~V}$ & $f_{m p p t}$ & $10 \mathrm{~Hz}$ \\
$r_{L}$ & $300 \mathrm{~m} \Omega$ & $L_{1}, L_{2}$ & $100 \mu \mathrm{H}$ & $K_{i,} K_{v}$ & $0.8,0.05$ \\
\hline
\end{tabular}

and $G\left(j \omega_{c}\right)$ is the open loop transfer function of the outer voltage or inner current control loops. The resultant transfer functions of the inductor current control $\left(C_{i-P V}\right)$ and the PV voltage control $\left(C_{v-P V}\right)$ are obtained as

$$
C_{i-P V}(s)=1.8+\frac{0.003}{s}+\frac{2 \omega s}{s^{2}+4 \pi s+(2 \omega)^{2}}
$$

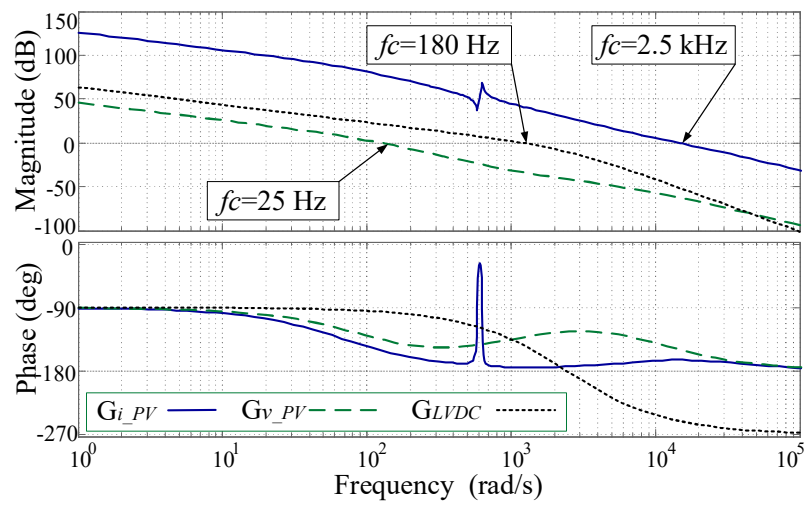

Fig.13. Magnitude and phase bode diagrams of the PV output voltage and dc bus voltage control loops

$$
C_{v-P V}(s)=0.1+\frac{24.7}{s}
$$

where $\omega=100 \pi$. As can be seen in (28), a resonant component at $\omega=100 \pi$ is added to the current control loop to increase the loop gain at $f=50 \mathrm{~Hz}$ and reduce the effect of low-frequency ripples propagated from the inverter bus [4]. This improves the stability of the PV operation point and MPPT performance. The bode diagrams of the inductor current and the PV voltage control loops are simulated for the converter unit for parameters illustrated in Table 6 and presented in Fig. 13.

The current loop has a crossover frequency of $f_{c i}=2.5 \mathrm{kHz}$ $\left(\omega_{c i}=16000 \mathrm{rad} / \mathrm{s}\right)$, gain margin of $60 \mathrm{~dB}$ and phase margin of $15^{\circ}$. On the other hand, the PV voltage control loop has a crossover frequency of $f_{c v}=25 \mathrm{~Hz}\left(\omega_{c v}=160 \mathrm{rad} / \mathrm{s}\right)$, a gain margin of $120 \mathrm{~dB}$ and the phase margin of $45^{\circ}$. Comparing the bandwidths of the voltage and current control loops shows that the current control loop has a much higher speed response compared to the voltage control loop $\left(f_{c v}<<f_{c i}\right)$ which means a faster reaction of the inductor current control loop.

\subsection{Design of Power Flow Controller in QAB Converter}

As presented in Fig.9, the conversion cell is modeled as an interleaved boost converter followed by a full bridge dc-ac converter. As the duty cycle $D^{\prime}$ is changing independently according to the MPPT requirement and is determined by $D$, to control the power flow from PV-linked cells to the HVDC bus and regulate $V_{L V D C}$, the phase shift angle $\left(\varphi_{X I}\right)$ can be used as another degree of freedom. Fig.14 illustrates the designed control system for the voltage regulation of the LVDC bus of the PV-linked conversion cells and the power flow to the HVDC bus. As can be seen, the reference voltage of the dc bus $\left(V^{*}{ }_{L V D C}\right)$ in each of the PV-linked cells is determined according to the reference signal generated based on the SVB rule presented in (10).

The PI controllers are determined similarly to the PV output control loop. However, the required cross-over frequency and the phase margin should be designed for slower dynamic response compared to that of PV output control to avoid the interference between the control loops and undesirable oscillations and instabilities during the transient times. The amplitude and phase bode diagrams of the designed control system are presented in Fig.13. As can be seen, the cross-over frequency of the loop is about $180 \mathrm{~Hz}$ which is much less than that of PV output control $(2.5 \mathrm{kHz})$. 


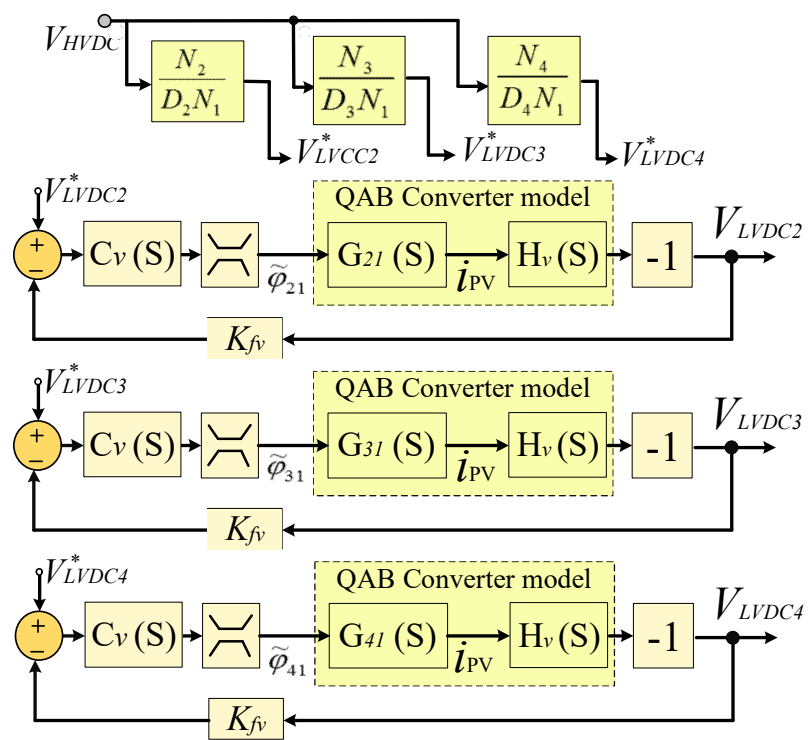

Fig.14. Block diagram of the DC bus voltage control system in the $Q A B$ converter

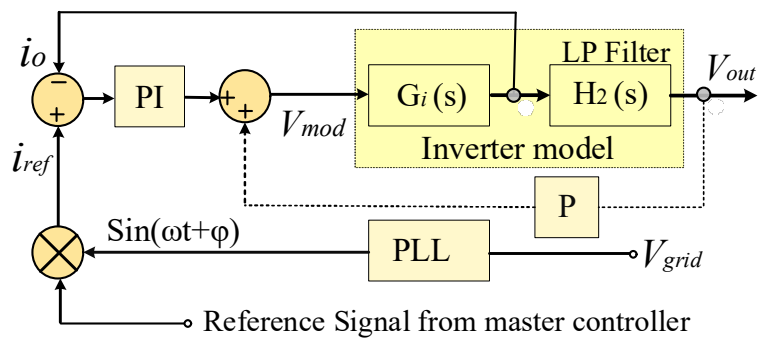

Fig.15. The control scheme of bi-directional single phase inverter

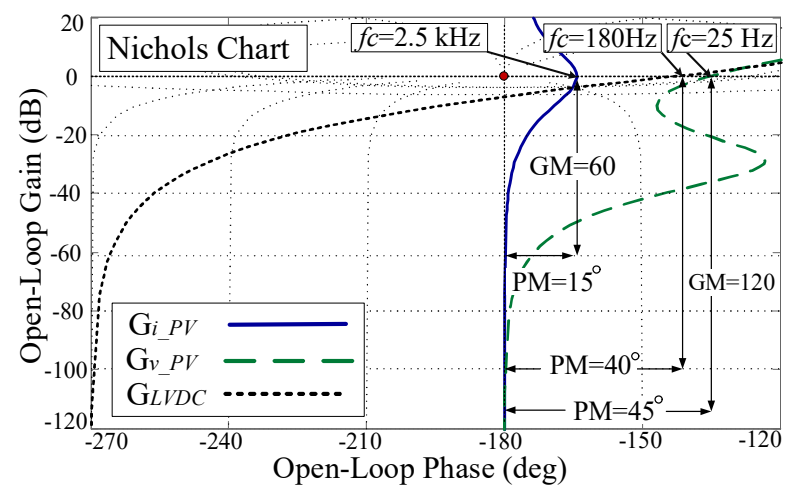

Fig.16. Nichols chart including phase and gain margins of the designed control loops.

In the inverter stage, a direct current-control technique is used to force the instantaneous output current of the inverter to follow the reference signal provided by the master controller as illustrated in Fig.15. The referenced signal is synchronized with the grid voltage by using a PLL block to provides high power factor, low THD and fast dynamic response [34], [35]. The PI compensator coefficients are determined similarly according to the required crossing frequency and phase margins of the current control loop. As the inverter current is controlled independently according to the provided reference, the output voltage amplitude varies according to the generated PV power. Therefore, the

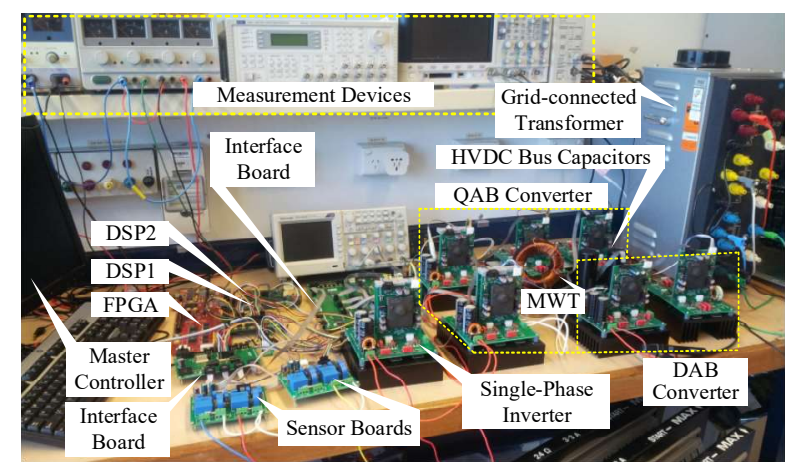

Fig.17. The experimentally developed conversion cell for the modular multi-level converter.

stabilization unit is used to balance the voltage level attributed to each phase of the MMC. The inverter stage is designed for operation in a unity power factor. However, operation in nonunity power factor with reactive power control using a d-q control technique is currently under study and remains for future publication. Fig.16 depicts the Nichols chart of the proposed control systems where the phase margin (PM), gain margin (GM) and cross-over frequencies are presented clearly.

\section{Experimental test results}

To validate the performance of the proposed converter unit for the PV-linked MMC, a $4.5 \mathrm{~kW}$ conversion unit including a PV-linked QAB dc-dc converter followed by a single-phase inverter was experimentally developed as presented in Fig.17. Two DSP controllers (C2000/TMS320F28335) are used to locally control the TAB converter and inverter. The system level control is performed by a PC using MATLAB. The lead acid batteries are used in stabilization unit considering their characteristics [39]. The voltage and current samples of all PV ports, inverter input and output are received by Hall-effect voltage (LEM/LV25-P) and current (LEM/LTSR25-NP) sensors. The MPPT process for each conversion cell is performed individually every $100 \mathrm{~ms}(\mathrm{f}=10 \mathrm{~Hz})$. The QAB converter is implemented by using IGBT switches (IKW40T120) and onboard driver integrated circuit VLA56701R. The single-phase inverter is realized by the full bridge unit with similar switches and the driver boards. Fig. 18 shows the experimentally measured waveforms of the interleaved boost converter and the resultant voltage and current in winding one and three of the MWT for two different operating conditions. The voltage and currents in ports two and four are similar to winding three due to the similarity in temperature and irradiation levels of all PV panels. Fig.19 (a) shows the experimental waveforms of the inverter output after passing through an output lowpass filter. However, in the case of multiple cascaded inverters, there is not any lowpass filter and the output voltage is a PWM signal where the output current is filtered out by series inductor in each phase. The voltage ripple on the LVDC and HVDC buses are also presented.As can be seen, for output ac power $\left(P_{O}=1.5 \mathrm{~kW}\right)$, the voltage ripple on the HVDC and LVDC buses are about $14 V_{\mathrm{P}}$ and 4 $V_{\mathrm{P}}$ respectively.

To show the MPPT performance, the PV voltage and current variation during a step change in irradiation from $\alpha=500 \mathrm{~W} / \mathrm{m}^{2}$ to $\alpha=800 \mathrm{~W} / \mathrm{m}^{2}$ are recorded and presented in Fig. 19 (b). As can be seen, the operation point of the PV closely tracks the irradiation change during transient time and the output power 


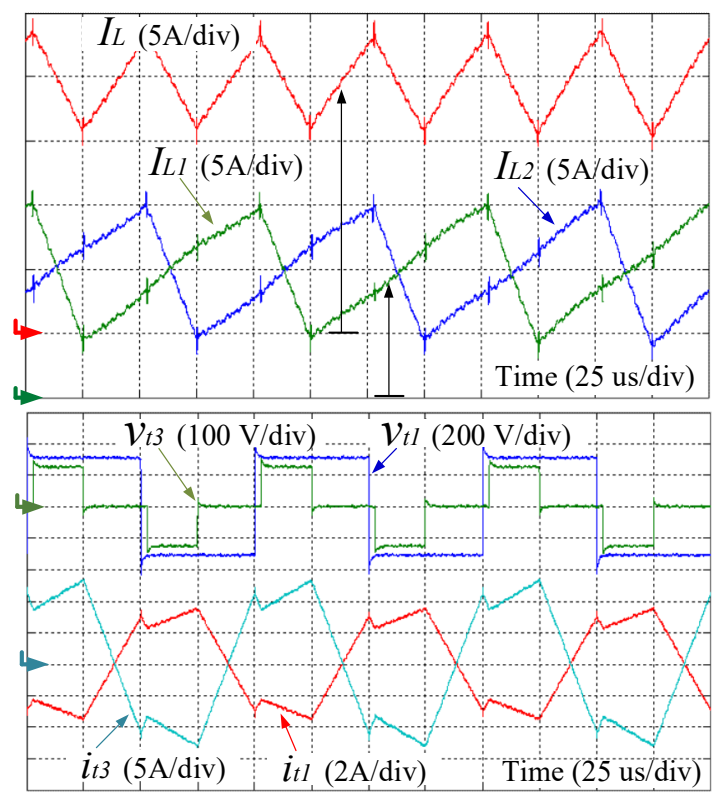

(a)
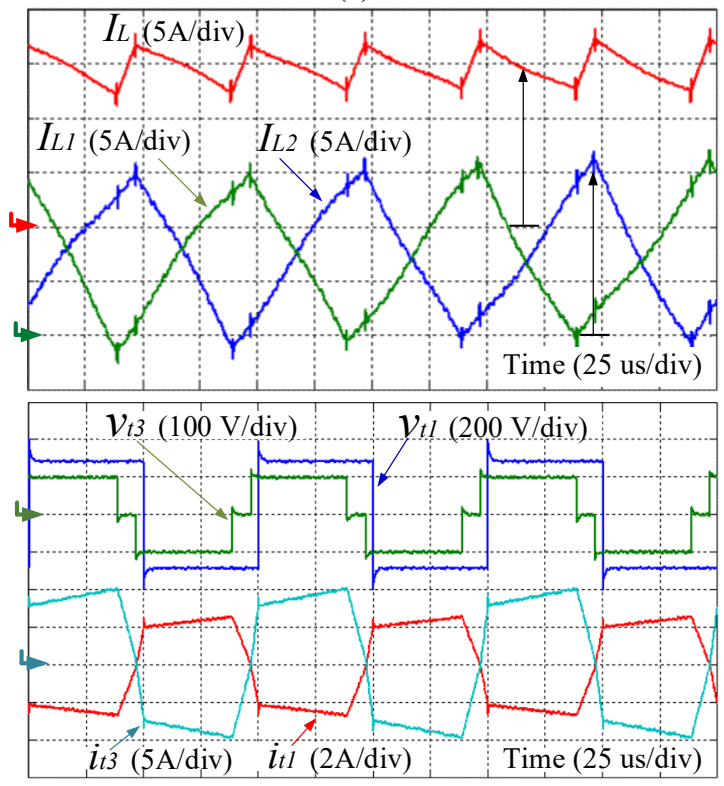

(b)

Fig.18. The experimentally measured waveforms of the inductor currents in the interleaved boost converters and the $T A B$ converter voltage and current for two cases: (a) $D=0.8$, $\varphi 31=\pi / 4, I_{L} \approx 19 \mathrm{~A}$ and (b) $D=0.6, \varphi 31=\pi / 6, I_{L} \approx 14 \mathrm{~A}$.

increases from $140 \mathrm{~W}$ to $350 \mathrm{~W}$. Fig.20 (a) shows the dynamic response of the proposed control systems when irradiation level changes from $\alpha=500 \mathrm{~W} / \mathrm{m}^{2}$ to $\alpha=800 \mathrm{~W} / \mathrm{m}^{2}$ and the PV output power from $140 \mathrm{~W}$ to $350 \mathrm{~W}$. The inverter output current increases from $5 A_{P-P}$ to $10 A_{P-P}$ due to the current oriented control mode while the PV output voltage remains almost constant. The voltage ripple of the HVDC and LVDC buses increases to $24 \mathrm{~V}_{\mathrm{P}-\mathrm{P}}$ and $8 \mathrm{~V}_{\text {P-P }}$ respectively. Fig.20 (b) shows similar waveforms when the irradiation level changes from $600 \mathrm{~W} / \mathrm{m}^{2}$ to $800 \mathrm{~W} / \mathrm{m}^{2}$. However, the inverter voltage drops when the output current follows the reference value provided by the master controller as PV generation is less than the expected value. The voltage ripple of the HVDC and LVDC busses follows the same trend. However, bus voltages

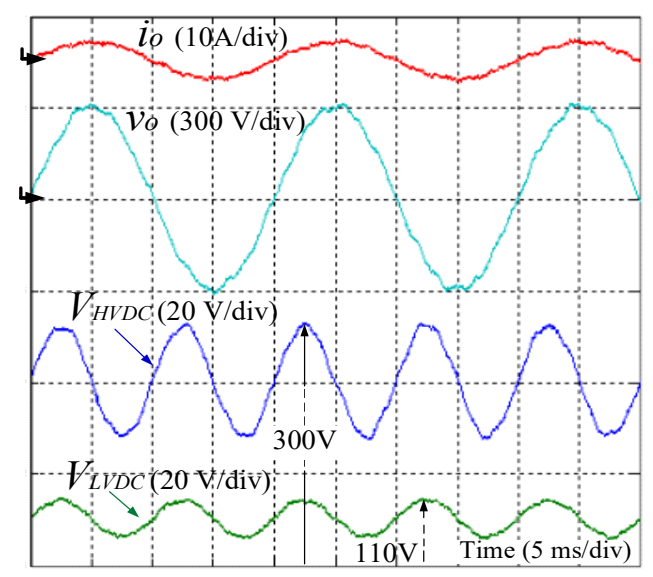

(a)

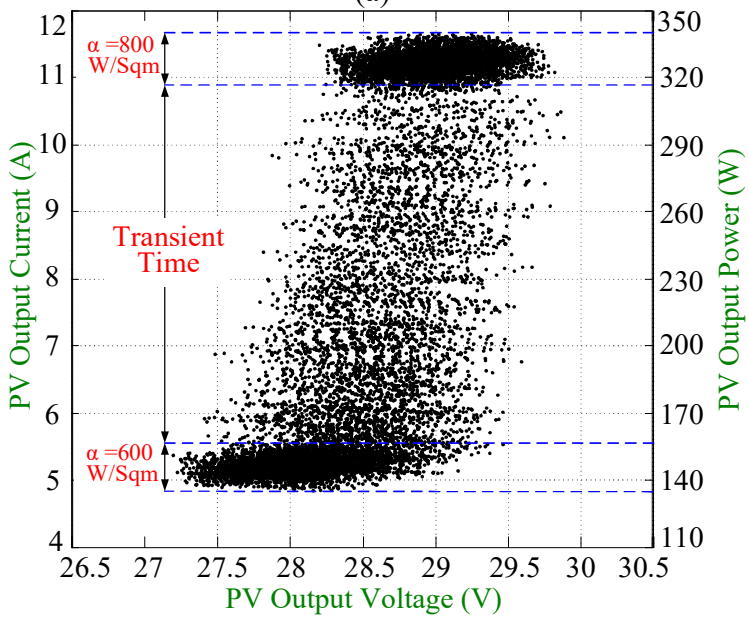

(b)

Fig.19. (a) The experimental waveforms of the inverter output current (io), output voltage (vo), and low-frequency ripples of the high voltage (VHVDC) and low-voltage (VLVDC) $d c$ buses. (b) Trajectory of MPPT operation for irradiation change from $600 \mathrm{~W} / \mathrm{sqm}$. to $800 \mathrm{~W} / \mathrm{sqm}$.

decrease due to the generated power limit. Fig.19 shows that using SVB technique improved the converter unit efficiency for the entire range of processing power and it increased by $5 \%$ at $P_{O}=3.5 \mathrm{~kW}$. On the other hand, using resonant element in the compensation block of the inductor current control loop, effectively reduced the low-frequency $(2 \omega)$ ripple in the PV output voltage by $4 \%$ at $1.5 \mathrm{~kW}$ power as illustrated in Fig. 20.

\section{Conclusion}

This paper proposed a topology of a PV-linked gridconnected MMC. A comparison has been performed to select a proper topology of $\mathrm{PV}$-linked dc-ac conversion cell from the feasible topologies, and the CFFB topology presented a better performance in terms of generated current ripple, reliability, power transfer range, cost, and size. The selected conversion cell then was studied in detail for the steady-state operation and control technique. Using SVB technique improved the system's efficiency by $5 \%$ and adding a resonant element as a compensator in the PV output current control loop, reduced the voltage ripple of the PV output by $4 \%$ and improved the MPPT performance. A prototype of the proposed converter unit is implemented and experimentally tested to validate the application in the suggested MMC topology. 


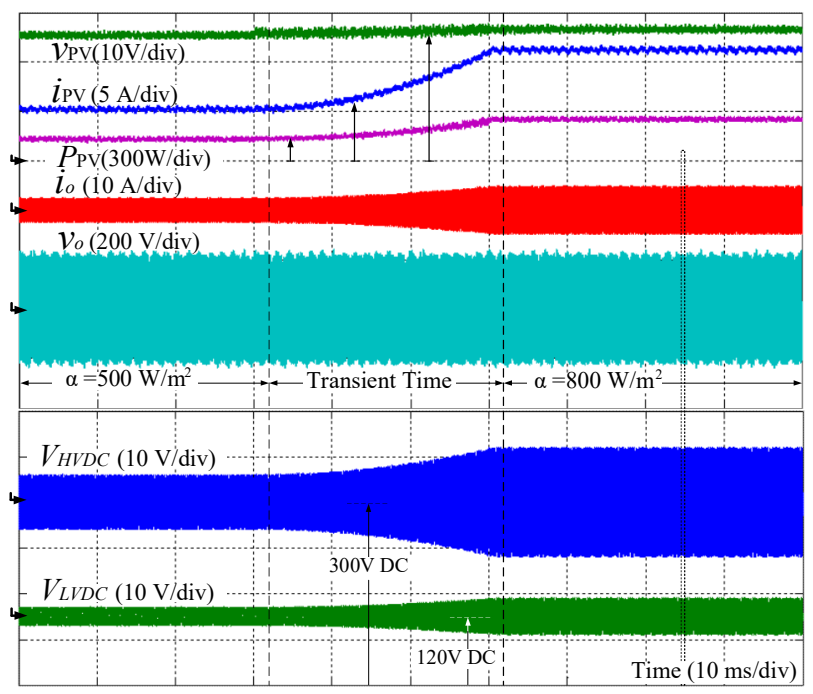

(a)

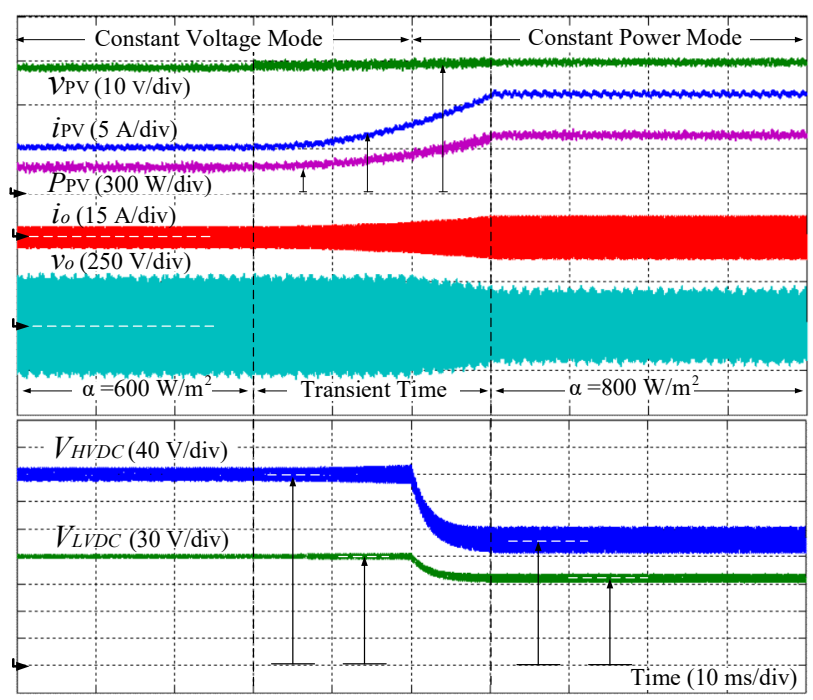

(b)

Fig.20. The dynamic response of the conversion cell against a change in the irradiation level of the PV port presenting $P V$ voltage, current and power, the inverter output voltage and current, $V_{H V D C}$ and $V_{L V D C}$. (a) from $500 \mathrm{~W} / \mathrm{sqm}$. to $800 \mathrm{~W} / \mathrm{sqm}$. (b) from $600 \mathrm{~W} / \mathrm{sqm}$. to $800 \mathrm{~W} / \mathrm{sqm}$

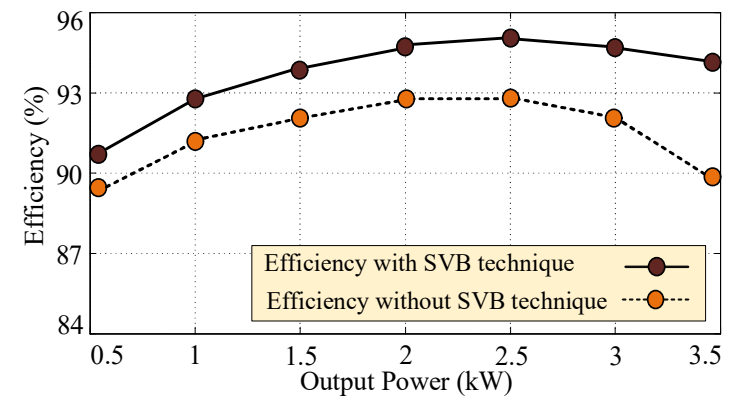

Fig.21. The measured efficiency of the conversion cell for two cases of with and without using SBVS technique.

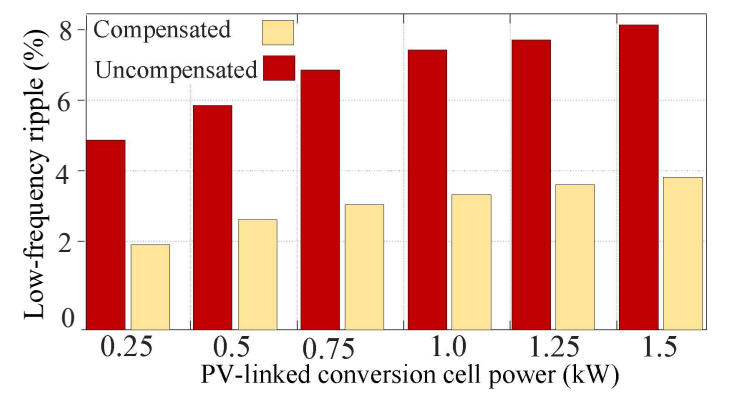

Fig.22. The effect of using resonant element on the lowfrequency ripple of the PV output voltage

\section{REEFERENCES}

[1] Dale, M.: 'Comparative Analysis of Energy Costs of Photovoltaic, Solar Thermal, and Wind Electricity Generation Technologies', Applied Science, 2013,3, pp 325-337

[2] Nademi, H., Das, A., Burgos, R. , and Norum, L. E. : 'A New Circuit Performance of Modular Multilevel Inverter Suitable for Photovoltaic Conversion Plants', IEEE Journal of Emerging and Selected Topics in Power Electronics, 2016, 4, 2, pp 393404

[3] Xiao, B., Hang, L., Mei, J., Riley, C., Tolbert, L. M., and Ozpineci, B. : 'Modular Cascaded H-Bridge Multilevel PV Inverter With Distributed MPPT for Grid-Connected Applications', IEEE Trans. Ind. Applications, 2015, 51, 2, pp 1722-1731.

[4] Malinowski, M., Gopakumar, K., Rodriguez, J. and Perezm, M. A., 'A Survey on Cascaded Multilevel Inverters', IEEE Trans. Ind. Electron., 2010, 57, 7, pp. 2197-2206

[5] Rodriguez, J., Lai, J.-S. and Peng, F. Z. 'Multilevel inverters: A survey of topologies, controls, and applications' IEEE Trans. Ind. Electron., 2002, 49, 4, pp. 724-738

[6] Liu, T. et al: 'Design and implementation of high efficiency control scheme of dual active bridge based 10kV/1MW solid state transformer for PV application' IEEE Trans. Power Electron., 2019, 34, 5, pp. 4223-4238

[7] She, X., Huang, A. Q. and Burgos, R. : 'Review of Solid-State Transformer Technologies and Their Application in Power Distribution Systems', IEEE Journal of Emerging and Selected Topics in Power Electronics, 2013, 1, 3, pp. 186-198.

[8] Kheraluwala, M. N., Gascoigne, R. W., Divan, D. M. and Baumann, E. D. : 'Performance characterization of a high-power dual active bridge DC-to-DC converter', IEEE Trans. Ind. Applications, 1992, 28, 6, pp. 1294-1301

[9] Falcones,S., Ayyanar, R. and Mao, X.: 'A DC-DC MultiportConverter-Based Solid-State Transformer Integrating Distributed Generation and Storage' IEEE Trans.Power Electron, 2013, 28, 5, pp. 2192-2203

[10] Costa, L. F., Hoffmann, F., Buticchi, G. and Liserre, M., 'Comparative Analysis of Multiple Active Bridge Converters Configurations in Modular Smart Transformer' IEEE Trans. Ind. Electron., 2019, 66, 1, pp. 191-202

[11] Jafari, M., Malekjamshidi, Z. and Zhu, J. 2019, 'Design and Development of a Multi-Winding High-Frequency Magnetic Link for Grid Integration of Residential Renewable Energy Systems', Applied Energy, 242, pp. 1209-1225. 
[12] Jafari, M., Malekjamshidi, Z., and Zhu, J., 'Optimal Energy Management of a Residential-based Hybrid Renewable Energy System Using Rule-based Real-time control and 2D Dynamic Programming optimization Method', Renewable Energy, 2019, 144, pp. 254-266

[13] Costa, L. F., Buticchi, G. and Liserre, M. 'Quad-Active-Bridge DC-DC Converter as Cross-Link for Medium-Voltage Modular Inverters' IEEE Trans. Ind. Applications, 2017, 53, 2, pp. 12431253

[14] Jafari, M., Malekjamshidi, Z., Lei, G., Wang, T., Platt, G. and Zhu, J., 'Design and Implementation of an Amorphous HighFrequency Transformer Coupling Multiple Converters in a Smart Microgrid', IEEE Trans. Ind. Electron., 2017, 64, 2, pp. 1028-1037

[15] Jafari, M., Malekjamshidi, Z., and Zhu, J., 'Copper Loss Analysis of a Multi-winding High-frequency Transformer for a Magnetically-coupled Residential Micro-grid' IEEE Trans. Ind. Applications', 2019, 55, 1, pp. 283-297

[16] Tao, H., Kotsopoulos, A., Duarte, J. L. and Hendrix, M. A. M. 'Family of multiport bidirectional DC-DC converters' IEE Proceedings - Elec. Power Applications, 2006, 153, 3, pp. 451458

[17] Michon, M., Duarte, J. L., Hendrix, M., and Simoes, M. G., 'A three-port bi-directional converter for hybrid fuel cell systems': proc. IEEE 35th Annual Power Electronics Specialists Conference, Aachen, Germany, 2004, pp. 4736-4742

[18] Tao, H., Duarte, J. L. Hendrix, M. A. M.: 'Three-port triple-half bridge bidirectional converter with zero voltage switching' IEEE Trans. Power Electron, 2008, 23, 2, pp 782-792

[19] Liu, X., Li, H. and Wang, Z. : 'A fuel cell power conditioning system with low-frequency ripple-Free input current using a control-oriented power pulsation decoupling strategy', IEEE Trans. Power Electron., 2014, 29, 1, pp. 159-169

[20] M. Jafari, Z. Malekjamshidi, J. Zhu and M. Khooban., 'A Novel Predictive Fuzzy Logic-Based Energy Management System for Grid-Connected and Off-Grid Operation of Residential Smart Microgrids,' IEEE Journal of Emerging and Selected Topics in Power Electronics, vol. 8, no. 2, pp. 1391-1404, June 2020, doi: 10.1109/JESTPE.2018.2882509.

[21] Wang, Z., Li, H. : 'An integrated three-port bidirectional dc-dc converter for PV application on a de distribution system', IEEE Trans. Power Electron., 2013, 28, 10, pp. 4612-4624

[22] Abu-Rub, H., Malinowski, M., Al-Haddad, K. : 'Photovoltaic Energy Conversion Systems', proc. IEEE Power Electronics for Renewable Energy Systems' Transportation and Industrial Applications, 2014, pp.

[23] Subudhi, B. and Pradhan, R. : 'A Comparative Study on Maximum Power Point Tracking Techniques for Photovoltaic Power Systems', IEEE Trans. Sustainable Energy, 2013, 4, 1, pp. 89-98

[24] Femia, N., Petrone, G., Spagnuolo, G. and Vitelli, M.: 'A technique for improving P\&O MPPT performances of doublestage grid-connected photovoltaic systems' IEEE Trans. Ind. Electron.,2009, 56, 11, pp. 4473-4482

[25] Jiang, S., Cao, D., Li, Y. and Peng, F. Z. : 'Gird-connected boosthalf bridge photoltaic microinverter system using repetitive current control and maximum power point tracking', IEEE Trans. Power Electron.,2012, 27, 11, pp. 4711-4722
[26] Ahmad, M. Agarwal, W. N. and Anand, S.: 'Online Monitoring Technique for Aluminum Electrolytic Capacitor in Solar PVBased DC System', IEEE Trans. Ind. Electron.,2016, 63, 11, pp. 7059-7066

[27] Chandra Mouli, G. R., Schijffelen, J., Bauer, P., Zeman, M. : 'Design and Comparison of a 10kW Interleaved Boost Converter for PV Application Using Si and SiC Devices', IEEE Journal of Emerging and Selected Topics in Power Electronics, 2016, 99, pp.1-1

[28] Jafari, M., Malekjamshidi, Z. and Zhu, J. G. : 'Analysis of operation modes and limitations of dual active bridge phase shift converter', proc. IEEE 11th Int. Conf. Power Electronics and Drive Systems, Sydney, NSW, 2015, pp. 393-398.

[29] Dhople, V. S., Davoudi, A., A. Dom'inguez-Garc'1a, D., Chapman, P. L. : 'A unified approach to reliability assessment of multiphase dc-dc converters in photovoltaic energy conversion systems', IEEE Trans. Power Electron., 2012, 27, 2, pp. 739-751

[30] Aghdam, F. H. and Abapour, M. : 'Reliability and Cost Analysis of Multistage Boost Converters Connected to PV Panels', IEEE Journal of Photovoltaics, 2016, 6, 4, pp. 981-989

[31] European Power Supply Manufacturers Association (EPSMA), 'Guidelines to Understanding Reliability Prediction', 2005

[32] MIL-HDBK-217F, 'Military Handbook for Reliability Prediction of Electronic Equipment, Department of Defense', Washington, DC, Jan. 1990.

[33] Jafari, M. Malekjamshidi, Z. Li, L. and Zhu, J.G., 'Performance analysis of full bridge, boost half bridge and half bridge topologies for application in phase shift converters', proc. Int. Conf. on Electrical Machines and Systems (ICEMS), Busan, 2013, pp. 1589-1595.

[34] Tao, H., Kotsopoulos, A., Duarte, J. L., and Hendrix, M. A. M. 'A Soft-Switched Three-Port Bidirectional Converter for Fuel Cell and Supercapacitor Applications', proc. 36th IEEE Power Elect. Specialists Conf., Recife, 2005, pp. 2487-2493.

[35] M.Jafari, Z.Malekjamshidi and, J.G.Zhu, A magnetically coupled multi-port, multi-operation-mode micro-grid with a predictive dynamic programming-based energy management for residential applications,' International Journal of Electrical Power \& Energy Systems, Vol.104, pp.784-796, 2019.

[36] Esram, T. and Chapman, P. L., 'Comparison of Photovoltaic Array Maximum Power Point Tracking Techniques', IEEE Trans. Energy Conversion, 2007, 22, 2, pp. 439-449

[37] Jafari, M., Malekjamshidi, Z., Lu, D. D. C., and Zhu, J.: 'Development of a Fuzzy-Logic-Based Energy Management System for a Multi-Port Multi-Operation Mode Residential Smart Micro-grid', IEEE Trans. Power Electronics, 2019, 34, 4, pp. 3283-3301

[38] C. L. Phillips and H. T. Nagle, Digital Control Systems Analysis and Design, 3rd ed. Englewood Cliffs, NJ, USA: Prentice-Hall, 1995.

[39] M. Jafari, G. Platt, Z. Malekjamshidi and J. G. Zhu, "Technical issues of sizing Lead-Acid batteries for application in residential renewable energy systems," 2015 4th Int. Conf. on Electric Power and Energy Conversion Systems (EPECS), Sharjah, 2015, pp. 1-6. 